\title{
- Prevalence of Thyroid Dysfunction Among Pregnant Women in First Trimester: A Hospital-Based Study From Mysuru, South India \\ IJCRR \\ Section: Healthcare
} ISI Impact Factor (2019-20): 1.628 IC Value (2019): 90.81 SJIF (2020) $=7.893$

(c) (i) (3)

Copyright@IJCRR

\section{Savitha V', Mamatha S $^{2}$, Madhu B ${ }^{3}$, Mahesh $\mathbf{M}^{4}$}

\begin{abstract}
'Assistant Professor of Medicine, JSS Medical College, JSS Academy of Higher Education and Research (Deemed to be a University), Mysuru, Karnataka State, India; ${ }^{2}$ Associate Professor of Obstetrics \& Gynecology, JSS Medical College, JSS Academy of Higher Education and Research (Deemed to be a University), Mysuru, Karnataka State, India; ${ }^{3}$ Associate Professor of Community Medicine, JSS Medical College, JSS Academy of Higher Education and Research (Deemed to be a University), Mysuru, Karnataka State, India; 4 Professor of Medicine,JSS Medical College,]SS Academy of Higher Education and Research (Deemed to be a University), Mysuru, Karnataka State, India.
\end{abstract}

\section{ABSTRACT}

Introduction: Hypothyroidism during pregnancy can lead to multiple adverse effects on both mother and child. Children born to untreated or undertreated mothers suffer profound effects on intellectual development. Subclinical hypothyroidism (SCH) is another important subset and knowledge of $\mathrm{SCH}$ in pregnancy is evolving. There are only a few studies on this aspect from South Asia.

Objectives: 1 . To estimate the prevalence and patterns of hypothyroidism in pregnant women 2 . To assess SCH and its association with clinic-demographic variables such as age, residence, consanguinity, duration of pregnancy, parity, diet, obesity and autoimmunity.

Methodology: This was a cross-sectional study conducted at JSS Hospital, a Tertiary Care Teaching Hospital, Mysore between Jan 2017 to June 2019. 500 women in the first trimester of pregnancy were included. Detailed history and clinical examination were recorded and blood samples were analysed for $\mathrm{Hb}, \mathrm{T} 3, \mathrm{~T} 4, \mathrm{TSH}$ and anti-TPO antibodies. Data were analyzed concerning associations.

Results: Out of 500, the results of 9 subjects were ineligible for analysis because of preanalytical lab error. The prevalence of Hypothyroidism in first trimester pregnant women was 156/491 (31.77\%), Of this9(5.76\%) had overt hypothyroidism and $147(94.23 \%)$ had subclinical hypothyroidism, and7 $(1.42 \%)$ had hyperthyroidism. Clinicodemographic variables as mentioned above were not significantly associated with $\mathrm{SCH}$ except the presence of anti-TPO antibody $(\mathrm{p}<0.001)$.

Conclusions: The prevalence rate of hypothyroidism was very high in our setting compared to that seen in other published reports. Positive Anti-TPO antibody was significantly associated with $\mathrm{SCH}$. There is a need for routine screening of hypothyroidism in the first trimester itself.

Key Words: Thyroid diseases, Gestation, Anti-TPO antibody, First trimester, Subclinical Hypothyroidism, Thyroid Gland

\section{INTRODUCTION}

Thyroid gland and function is significantly impacted during Pregnancy. The thyroid gland enlarges in size by a tenth of its pre-pregnancy state. The increase in size is more pronounced in iodine-deficient populations. ${ }^{1}$ Along with the increased requirement of iodine, the production of thyroid hormone also increases by as much as $50 \%{ }^{2}$ The stress of pregnancy pushes the gland into hypofunction especially in those with an already limited thyroid reserve.
$2.5 \%$ of pregnant women have hypothyroidism according to literature from West. ${ }^{3}$ Data for the Indian population is scarce with only a few studies done on the Indian population. The prevalence rates ranged from $4.8 \%$ to $11 \%$ in the Indian studies. ${ }^{4,5}$ In a large study ${ }^{6}$ the prevalence of hypothyroidism in pregnancy was $13.13 \%$ and the majority of these hypothyroid pregnant women had subclinical hypothyroidism.

Both mother and child are affected by Hypothyroidism. Children born to untreated or undertreated mothers suffer profound effects, especially on intellectual development. ${ }^{6}$ Miscarriages

\section{Corresponding Author:}

Dr. Savitha V, No 16, Swasthi, Block no 7, Shivashakthi Road, Shakthi Nagar, Mysuru 570029, Karnataka State, India. Phone: 8095148464; Email: dr.savitha2014@gmail.com
ISSN: 2231-2196 (Print)
ISSN: 0975-5241 (Online)

Received: 30.06 .2021

Revised: 02.08 .2021

Accepted: 13.09 .2021

Published: 01.12 .2021 
are common in hypothyroid women. Even those with normal thyroid function tests results have an increased risk of miscarriages if they have TPO antibodies. Subclinical hypothyroidism is associated with an increased risk of anaemia during pregnancy and increased risk for preterm delivery before 34 gestational weeks and low birth weight babies.

There are not many studies on the Indian population from South India, hence this study was taken up with objectives of 1. To estimate the prevalence and patterns of hypothyroidism in pregnant women in a tertiary care teaching hospital setting in South India 2. To assess SCH and its association with clinic-demographic variables such as age, residence(urban/ rural), consanguinity, duration of pregnancy, parity, diet pattern, obesity and autoimmunity.

\section{METHODOLOGY}

This was a cross-sectional study conducted between Jan 2017 to June 2019 at JSS Hospital, a tertiary care teaching and research hospital attached to JSS Medical College .500 consecutive pregnant women aged 18-45 years in the first trimester of pregnancy were recruited. Informed written consent was taken from all women. Ethical Clearance was obtained from JSS Medical College Institutional Ethical Committee[IEC/14/6047].

Pregnant women who had any past or present history of thyroid dysfunction/disease, family history of thyroid disease, previous head or neck irradiation, usage of drugs such as levothyroxine, methimazole, iodide, lithium, amiodarone and corticosteroids, patients diagnosed with autoimmune and connective tissue diseases were excluded from the study. Detailed history and clinical examination were recorded in clinical proforma. Age, residence, consanguinity, duration of pregnancy, parity, hypothyroid symptoms and diet history were collected. Height, Weight, Body Mass Index, Blood Pressure and presence of goitre were all noted.

Venous blood samples of $5 \mathrm{ml}$ were collected under aseptic precautions and were sent for analysis of Hemoglobin\%, T3, T4, TSH and anti-TPO antibodies. T3, T4, TSH and anti-TPO antibodies were measured by the chemiluminescence method. TSH value $>2.5 \mu \mathrm{IU} / \mathrm{ml}$ but less than or equal to $10 \mu \mathrm{IU} / \mathrm{ml}$ with normal T4 are considered to have Subclinical Hypothyroidism, $\mathrm{TSH}$ value $>10 \mu \mathrm{IU} / \mathrm{ml}$ irrespective of $\mathrm{T} 4$ values and TSH value $>2.5 \mu \mathrm{IU} / \mathrm{ml}$ with low T4 values are considered to have Overt Hypothyroidism [American Thyroid Association and National Guidelines]. ${ }^{24}$ The association of Subclinical Hypothyroidism with the above variables were statistically analysed.

\section{STATISTICAL ANALYSIS}

Data collected were entered in Microsoft Excel and analysed using SPSS version 22. Descriptive statistical meas- ures like percentage, mean and standard deviation were calculated. Inferential statistical tests like the Chi-square test, Two-way ANOVA were used wherever relevant and statistical significance at the $\mathrm{p}$-value of $<0.05$ was considered significant.

\section{RESULTS}

Out of 500 women included in the study, 9 were excluded because of pre-analytical error, hence there were 491 pregnant women in the first trimester of pregnancy. Most of them, 403 $(82 \%)$ were in the age group $21-30$ years, $363(74.75 \%)$ belonged to the urban category, most i.e,481(98\%) were literate and $466(95 \%)$ were homemakers. $412(84 \%)$ had married when aged between 18-25 years age,407(83\%) had a nonconsanguineous marriage, $228(46 \%)$ were primigravida and $263(53 \%)$ were multigravida, only $4(0.8 \%)$ had previous caesarean section and 51(10\%) had the previous history of irregular menstrual cycles.370(75\%) were non-vegetarians, $418(85 \%)$ had an intake of cauliflower and cabbage weekly once.227(46\%) had normal BMI,107(21\%) were overweight,65(12\%) were obese and 92(18\%) were underweight [Table 1].

Among 491 pregnant women,156(31.77\%) were hypothyroid out of which $9(5.76 \%)$ had overt hypothyroidism and $147(94.23 \%)$ had subclinical hypothyroidism, $7(1.42 \%)$ had thyrotoxicosis [Figure 2].

Predominant symptom in Hypothyroid women was fatigue $(35.6 \%)$ followed by hair $\operatorname{loss}(31.7 \%)$,cold intolerance (16.9\%), dry $\operatorname{skin}(6.72 \%)$,constipation(2.65\%), weight gain(2.24\%) and poor memory(2.04\%)[Figure $1]$. Most of them belonged to age group 21-30years (123$78 \%$ ), urban residency (123-78\%), were multigravida (84$53 \%), 131(83 \%)$ had non-consanguineous marriage, only $20(7.8 \%)$ had previous history of irregular menstrual cycles and $154(99 \%)$ had uneventful pregnancy previously. 125 $(80 \%)$ were non-vegetarians, about

$131(83 \%)$ women had intake of cauliflower and cabbage weekly once [Table 2].

Among 156 hypothyroid women, 74(47\%) had normal BMI, $23(14 \%)$ were underweight, $41(26 \%)$ were overweight and $18(11 \%)$ were obese.113 (72.43\%) had normal HB, $43(27.56 \%)$ were anaemic. $20(12.82 \%)$ were found to be anti-TPO antibody positive.

Chi-square analysis indicated that age, residence, consanguinity, weeks of pregnancy, parity, diet and obesity were not significantly associated with subclinical hypothyroidism. However anti-TPO antibody was significantly associated with $\mathrm{SCH}(0.001)[$ Table 3]. 


\section{DISCUSSION}

In our study, the prevalence rate of hypothyroidism was found to be $31.77 \%$ which is significantly higher compared to previous studies. In Dhanwal et al. study conducted in India, prevalence was $13.13 \%$ and the majority were subclinical. ${ }^{6}$ Another study conducted by Prasad et al. in Delhi reported a $14.3 \%$ prevalence of hypothyroidism during the first trimester. ${ }^{25}$ Another study conducted in a tertiary hospital in India on a total of 461 women showed a higher number of cases of SCH. ${ }^{23}$ In our study also, the majority of cases were subclinical hypothyroidism similar to other studies. In a study done on Caucasian women by Knight et al. ${ }^{7}$, the prevalence was found to be $13.9 \%$. In other countries, the prevalence of SCH ranged from $2 \%$ to $2.5 \%$ in the U.S, $6.8 \%$ in Belgium, $13.7 \%$ in Spain and $8 \%$ in Congo. ${ }^{8-10}$ In Iran, the prevalence of hypothyroidism was found to be $4.2 \%$, of which $89.1 \%$ of cases were subclinical similar to our study. ${ }^{11}$

The reason for the higher incidence in our study might be low TSH cut off value $>2.5 \mu \mathrm{IU} / \mathrm{ml}$ is used in our study as other studies have used TSH $>4 \mu \mathrm{IU} / \mathrm{ml}$ as cut off. Factors such as iron deficiency and iodine deficiency might also have played a role in the difference between our study and others. Excessive iodine intake, ethnicity, presence of goitrogens in food and selenium deficiency have also been associated with hypothyroidism. ${ }^{14}$

Subclinical hypothyroidism in pregnancy has a significant impact on pregnancy outcomes. Several studies have reported that it is associated with pregnancy complications such as gestational diabetes (GDM), hypertension, and preeclampsia. ${ }^{12,13}$ In a study conducted on 508 pregnant women in Pakistan, $\mathrm{SCH}$ was shown to be strongly associated with GDM. High TSH levels were reported in $61.5 \%$ of women with GDM compared to $6 \%$ in healthy controls. ${ }^{15}$ Women with $\mathrm{SCH}$ were found to be twice as likely to deliver prematurely compared to subjects whose thyroid function tests were normal. These women also had a 3 times higher chance of developing placental abruption. ${ }^{16}$ Other studies have reported that pregnant women with $\mathrm{SCH}$ are more likely to suffer a miscarriage, especially during the first 20 weeks of gestation. ${ }^{17}$

Maraka et al. ${ }^{18}$ found that $\mathrm{SCH}$ affected both the mother during pregnancy and also neonatal outcomes. Intrauterine growth restriction, small for gestational age, low birth weights, and low Apgar scores were all reported in neonates whose mothers were $\mathrm{SCH}$ patients.

A meta-analysis by Fan et al, ${ }^{20}$ which included 6 studies, showed that thyroid abnormalities in pregnant women may have an impact on the neuropsychological development of children. There is also increasing evidence linking $\mathrm{SCH}$ to attention deficit hyperactivity disorder (ADHD) and autistic symptoms in offspring. ${ }^{21,22}$
To find out the causes for $\mathrm{SCH}$, we tried to find out any association between clinic demographic variables and $\mathrm{SCH}$. As age increased, there was no increase in hypothyroidism in our study as all women were less than 40 years. Hypothyroidism was more in multigravida compared to primigravida but there was no significant statistical association. Hypothyroidism was more prevalent in normal BMI women(74) compared to obese women(59) in our study while previous studies have shown that hypothyroidism was common among obese women. ${ }^{19}$ Subclinical hypothyroidism is most often caused by autoimmune (Hashimoto) thyroiditis. ${ }^{26}$ In our study also, subclinical hypothyroidism was significantly associated with anti-TPO antibodies $(\mathrm{p}<0.001)$. Even dietary practices had no significant association with hypothyroidism. In an extensive search through databases, we could not find any article showing the association between $\mathrm{SCH}$ and variables like age, residence, consanguinity, weeks of pregnancy, parity and diet. Our study may well be the first to look into this and our results do not show any correlation. Further research has to be done to find out causal factors for $\mathrm{SCH}$.

The strengths of this study are the large sample size and the that all samples were analysed at the same central laboratory. A few limitations are that this being a cross-sectional study, the results may be subject to non-response bias. The study did not carry out tests for other antibodies such as antithyroglobulin antibody and thyroid receptor stimulating immunoglobulins which would have thrown more light on the precise role of autoimmunity and thyroid dysfunction in pregnancy.

\section{CONCLUSIONS}

The prevalence of hypothyroidism was very high in our setting compared to that seen in other published reports. There was no association found between $\mathrm{SCH}$ and factors such as age, residence, consanguinity, weeks of pregnancy, parity, dietary practices and obesity. Positive Anti-TPO antibody was significantly associated with $\mathrm{SCH}$.

Because of the high prevalence of subclinical hypothyroidism both in our study and earlier studies from other regions of India, it is recommended that a National sub-clinical hypothyroidism screening programme must be taken up for benefit of pregnant women and their offspring.

\section{ACKNOWLEDGEMENTS}

We express our sincere thanks to Dr Suma K. B, Head, Dept of OBG, for her departmental support. We are grateful to Dr. MVSST. Subbarao, Professor, Dept of Biochemistry for his immense cooperation in lab analysis. We extend our due thanks to Dr M Guruswamy, Superintendent, JSS Hospital 
and our Principal Dr H. Basavana Gowdappa for his encouragement and help in obtaining Research funds. The authors acknowledge the immense help received from the scholars whose articles are cited and included in references of this manuscript. The authors are also grateful to authors mentioned in references from where the literature for this article has been reviewed and discussed."

Conflict of interest: All authors declare no Conflict of interest

Ethics: There is no ethical violation

Source of Funding: The study was in major part-funded by Mysore Physicians Medical Research Trust (MPMRT)a nonprofit academic wing of Association of Physicians of India Mysore Chapter Mysore and another part by Karnataka Chapter of Association of Physicians of India, Bangalore

Guarantor: Dr. Savitha V will act as guarantor of this article on behalf of all co-authors.

Authors' Contribution: Dr. Savitha. V collected data, analysed and wrote the article.

Dr. Mamatha helped in the collection of data.

Dr. Madhu. B helped in data analysis.

Dr. Mahesh. M guided me in all aspects of the study.

\section{REFERENCES}

1. Van Raaij JM, Vermaat-Miedema SH, Schonk CM, Peek ME, Hautvast JG. Energy requirements of pregnancy in The Netherlands. Lancet. 1987; 2:953-5.

2. Glinoer D. The regulation of thyroid function in pregnancy: Pathways of endocrine adaptation from physiology to pathology. Endocr Rev. 1997; 18:404-33.

3. LeBeau SO, Mandel SJ. Thyroid disorders during pregnancy. Endocrinol Metab Clin North Am.2006; 35:117-36.

4. Nambiar V, Jagtap VS, Sarathi V, Lila AR, Kamalanathan S, Bandgar TR, et al. Prevalence and impact of thyroid disorders on maternal outcome in Asian-Indian pregnant women. J Thyroid Res 2011. 2011:429097.

5. Sahu MT, Das V, Mittal S, Agarwal A, Sahu M. Overt and subclinical thyroid dysfunction among Indian pregnant women and its effect on maternal and fetal outcome. Arch Gynecol Obstet. 2010; 281:215-20.

6. Dhanwal .D.K, Bajaj .S, Rajput. R, Subramaniam .K.A.V, Chowdhury. S, Mala .D et al. Prevalence of hypothyroidism in pregnancy: An epidemiological study from 11 cities in 9 states of India. Indian J Endocrinol Metab 2016 May-Jun; 20(3): 387390

7. Knight BA, Shields BM, Hattersley AT, Vaidya B. Maternal hypothyroxinaemia in pregnancy is associated with obesity and adverse maternal metabolic parameters. Eur J Endocrinol. 2016; 174:51-57

8. Maraka S, Ospina NMS, O'Keeffe DT. Subclinical hypothyroidism in pregnancy: A systematic review and meta-analysis. Thyroid. 2016; 26:580-590
9. Klubo-Gwiezdzinska J, Burman KD, Van Nostrand D, Wartofsky L. Levothyroxine treatment in pregnancy: indications, efficacy, and therapeutic regimen. J Thyroid Res. 2011; 2011:843591.

10. Habimana L, Twite KE, Daumerie C. High prevalence of thyroid dysfunction among pregnant women in Lubumbashi, Democratic Republic of Congo. Thyroid Off J Am Thyroid Assoc. 2014;24: 568-575

11. Yassaee F, Farahani M, Abadi AR. Prevalence of subclinical hypothyroidism in pregnant women in Tehran-Iran. Int J Fertil Steril. 2014;8: 163-165

12. Gong L-L, Liu H, Liu L-H. Relationship between hypothyroidism and the incidence of gestational diabetes: A meta-analysis. Taiwan J Obstet Gynecol. 2016;55: 171-175.

13. Wilson KL, Casey BM, McIntire DD, Halvorson LM, Cunningham FG. Subclinical thyroid disease and the incidence of hypertension in pregnancy. Obstet Gynecol. 2012;119: 315-320.

14. Teng X, Shan Z, Chen Y, Lai Y, Yu J, Shan L, et al. More than adequate iodine intake may increase subclinical hypothyroidism and autoimmune thyroiditis: A cross-sectional study based on two Chinese communities with different iodine intake levels. Eur J Endocrinol. 2011;164: 943-50

15. Fatima SS, Rehman R, Butt Z. Screening of subclinical hypothyroidism during gestational diabetes in Pakistani population. J Matern-Fetal Neonatal Med. 2016;29: 2166-2170

16. Casey BM, Dashe JS, Wells CE. Subclinical hypothyroidism and pregnancy outcomes. Obstet Gynecol. 2005; 105:239-245

17. Negro R, Schwartz A, Gismondi R, Tinelli A, Mangieri T, Stagnaro-Green A. Increased pregnancy loss rate in thyroid antibody negative women with TSH levels between 2.5 and 5.0 in the first trimester of pregnancy. J Clin Endocrinol Metab. 2010; 95:E44-48.

18. Maraka S, Ospina NMS, O'Keeffe DT.Subclinical hypothyroidism in pregnancy: A systematic review and meta-analysis. Thyroid. 2016;26: 580-590.

19. Mehran L, Amouzegar A, Rahimabad PK, Tohidi M, Tahmasebinejad Z, Azizi F. Thyroid function and Metabolic Syndrome: a population-based Thyroid study. Horm Metab Res. 2017 Mar;49(3):192-200.

20. Fan X, Wu L. The impact of thyroid abnormalities during pregnancy on subsequent neuropsychological development of the offspring: a meta-analysis. J Matern-Fetal Neonatal Med. 2016;29: 3971-3976.

21. Modesto T, Tiemeier H, Peeters RP. Maternal Mild Thyroid Hormone Insufficiency in Early Pregnancy and Attention-Deficit/ Hyperactivity Disorder Symptoms in Children. JAMA Pediatrics. 2015;169: 838-845.

22. Román GC, Ghassabian A, Bongers-Schokking JJ. Association of gestational maternal hypothyroxinemia and increased autism risk. Ann Neurol. 2013;74: 733-742.

23. Shatha A, Al Shanqeeti, Yasser N, Alkhudairy. Prevalence of subclinical hypothyroidism in pregnancy in Saudi Arabia. Saudi Med Journal.2018 Mar; 39(3): 254-260.

24. National Guidelines for Screening of Hypothyroidism during Pregnancy-Maternal Health Division, Ministry of Health and Family Welfare, Government of India- December 2014

25. Dhanwal DK, Prasad S, Agarwal AK, Dixit V, Banerjee AK. High prevalence of subclinical hypothyroidism during the first trimester of pregnancy in North India. Indian J Endocrinol Metab. $2013 ; 17: 281-4$.

26. Biondi B, Cappola AR, Cooper DS. .Subclinical hypothyroidism- A Review. J Ame Med Ass. 2019 Jul 9;322(2):153-160. 
Table 1: Characteristics of study subjects

\begin{tabular}{ll} 
Characteristics of study subjects & $\mathbf{n}-491(100 \%)$ \\
Age & $21-30$ years $-403(82.07 \%)$ \\
Residency & Urban-363(73.93\%) \\
Literacy & Literate-481(97.96\%) \\
Occupation & Housewives-466(94.90\%) \\
Age of marriage & $18-25$ years-412 $(83.91 \%)$ \\
Consanguinity & Non consaguinousmarriage-407(82.89\%) \\
Gravida & Primi-228(46.43\%), multi-263(53.56\%) \\
Caesarean section & $4($ o.81\%) \\
Diet & Non vegetarians-370(75.35\%) \\
Cauliflower and cabbage intake & Weekly once in $418(85.13 \%)$ \\
BMI & Normal-227(46.23\%) \\
& Overweight-107(21.79\%) \\
& Obese-65(13.23\%) \\
\hline
\end{tabular}

Table 2: Characteristics of Hypothyroid women

Characteristics of Hypothyroid women

\section{$\mathrm{n}-156(31 \cdot 77 \%)$}

Age

Residency

21-30 years-123 $(78.84 \%)$

Urban-123(78.84\%)

Literacy

Literate-152(97.43\%)

Occupation

Housewives-152(97.43\%)

Age of marriage

18-25 years- $128(82.05 \%)$

Consanguinity

Non consaguinousmarriage-131(83.97\%)

Gravida

Primi-46(15\%), multi-84(53.84\%)

Caesarean section

Diet

Cauliflower and cabbage intake

BMI

Goitre
$2(1.2 \%)$

Non veg-125(80.12\%)

Weekly once $-131(83.97 \%)$

Normal-74(47.43\%)

Overweight-41(26.28\%)

Obese-18(11.53\%)

Underweight-23(14.74\%)

$10(6.41 \%)$

Table 3: Factors associated with Subclinical hypothyroidism

$\begin{array}{lccc} & \text { SCH } & & \text { p-value } \\ \text { Age } & \text { No } & \text { Yes } & \\ <=20 & 42 & 24 & 73 \\ 21-25 & 202 & 43 & 0.06 \\ 26-30 & 78 & 5 & 2\end{array}$


Table 3: (Continued)

$\begin{array}{lcccc} & \text { SCH } & & \text { p-value } \\ \text { Residence } & \text { No } & \text { Yes } & & 0.20 \\ \text { Urban } & 243 & 115 & 32 & \end{array}$

\section{Consanguinity}

No

Yes

Weeks of pregnancy

0-4

5-8

9-12

\section{Gravida}

Primi

155

Multi

Veg/NonVeg

Non-veg

Veg

\section{Cauliflower/Cabbage}

None

Weekly once

Fortnight once

Monthly once

Rare

BMI

$<18.5$

18.5-22.9

23-24.9

245-27.9

28-29.9

$>30$

\section{ANTI TPO AB}

$<=34$

325

54

4

178

152

179

244

90

\section{6}

286

24

15

3

68

153

66

31

10

6
123

24

117

30

81

64

0.91

0.96

2
0.76

124

13

5

3

22

71

39

10

2

3
$>34$

9

133

$<0.001$ 


\section{SYMPTOMS}

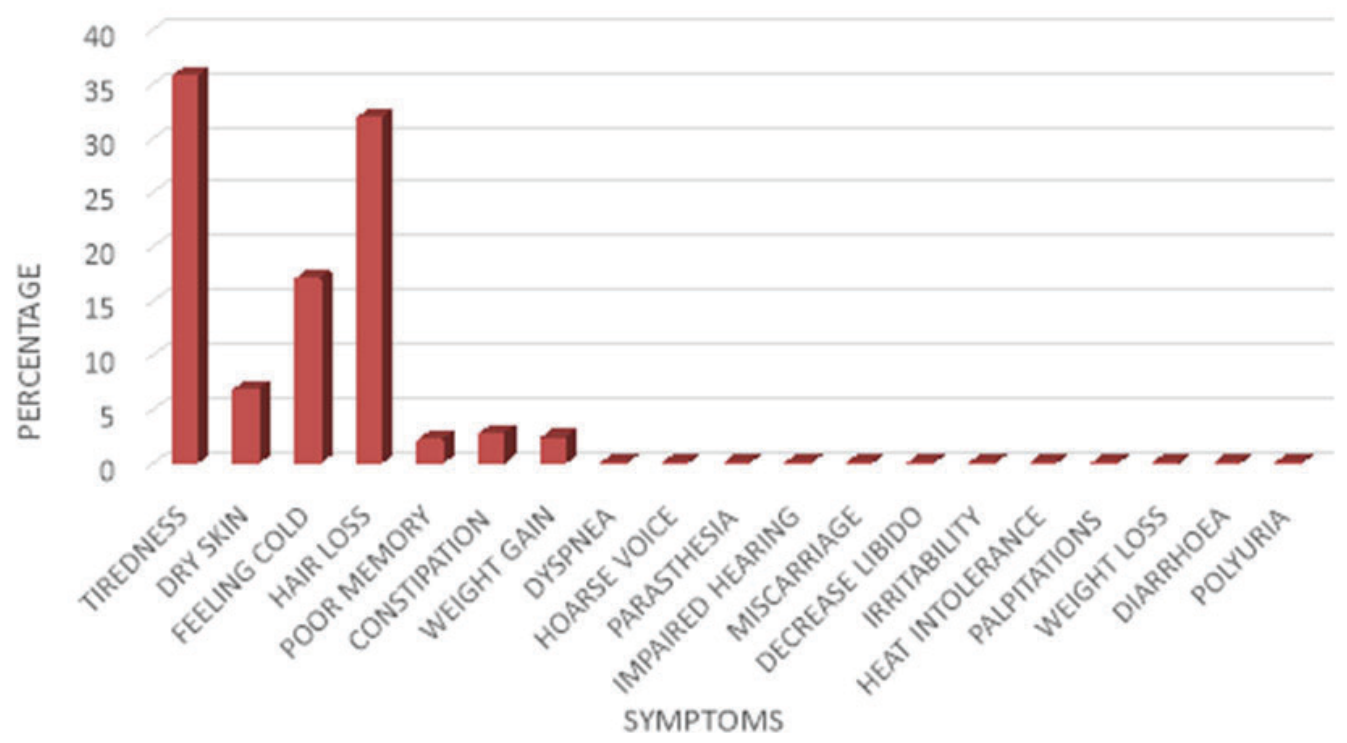

Figure 1: Symptoms of Hypothyroidism.

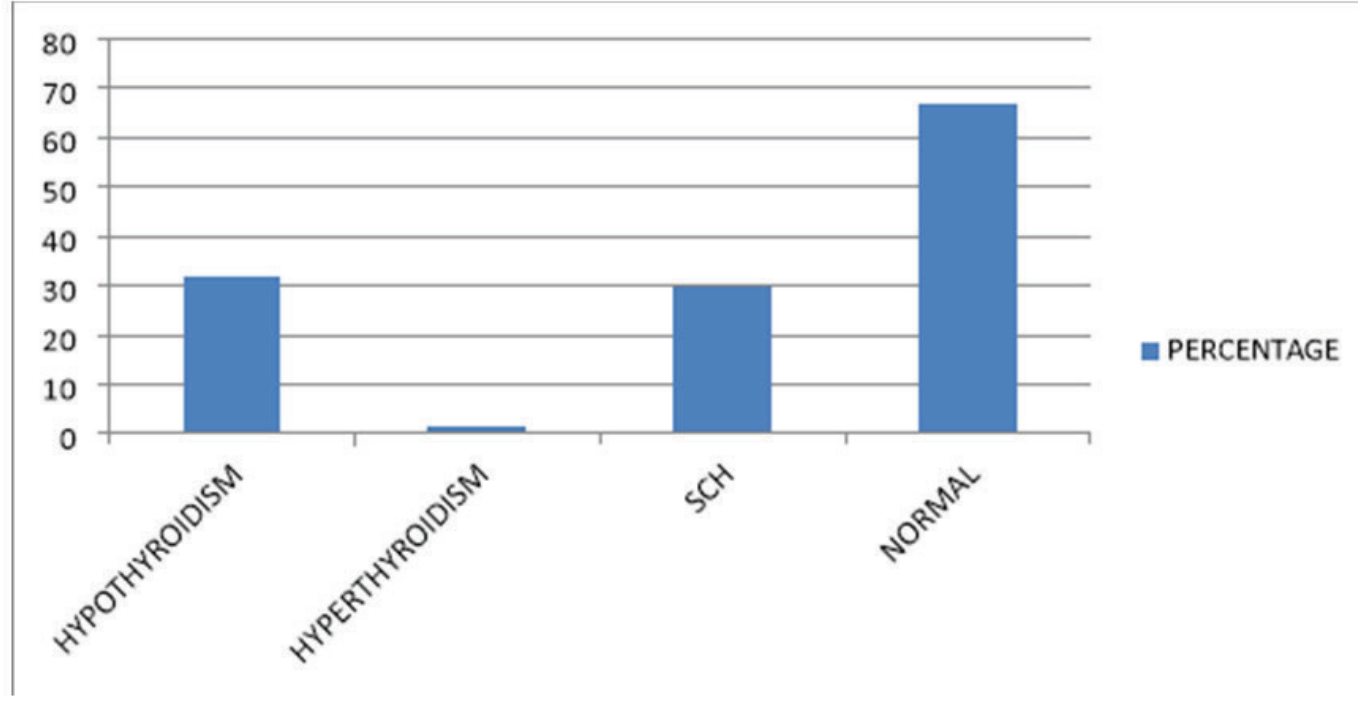

Figure 2: Thyroid functional status. 